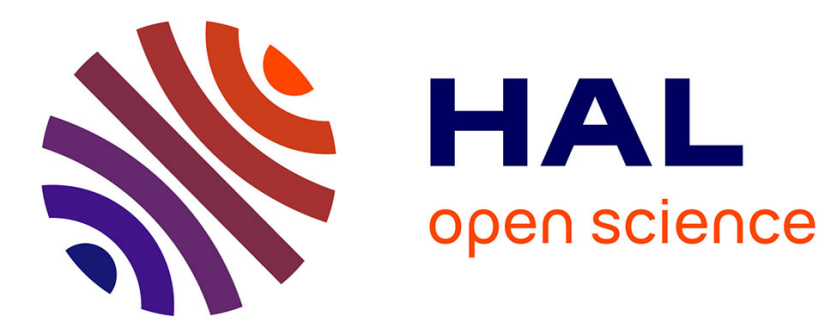

\title{
Des émeutes à une crise politique: les ressorts de la politisation des mobilisations en Algérie en 1988
}

\author{
Myriam Ait-Aoudia
}

\section{To cite this version:}

Myriam Aït-Aoudia. Des émeutes à une crise politique: les ressorts de la politisation des mobilisations en Algérie en 1988. Politix, 2015, Protagonisme et crises politiques, 112, pp.59-82. 10.3917/pox.112.0059 . halshs-01348697

\section{HAL Id: halshs-01348697 https://shs.hal.science/halshs-01348697}

Submitted on 25 Jul 2016

HAL is a multi-disciplinary open access archive for the deposit and dissemination of scientific research documents, whether they are published or not. The documents may come from teaching and research institutions in France or abroad, or from public or private research centers.
L'archive ouverte pluridisciplinaire HAL, est destinée au dépôt et à la diffusion de documents scientifiques de niveau recherche, publiés ou non, émanant des établissements d'enseignement et de recherche français ou étrangers, des laboratoires publics ou privés. 


\title{
DES ÉMEUTES À UNE CRISE POLITIQUE : LES RESSORTS DE LA POLITISATION DES MOBILISATIONS EN ALGÉRIE EN 1988
}

Myriam Aï-Aoudia

\author{
De Boeck Supérieur | « Politix »
}

2015/4 nº 112 | pages 59 à 82

ISSN 0295-2319

ISBN 9782807300965

Article disponible en ligne à l'adresse :

http://www.cairn.info/revue-politix-2015-4-page-59.htm

\section{Pour citer cet article :}

Myriam Aït-Aoudia, « Des émeutes à une crise politique : les ressorts de la politisation des mobilisations en Algérie en 1988 », Politix 2015/4 (n 112), p. 59-82. DOI 10.3917/pox.112.0059

Distribution électronique Cairn.info pour De Boeck Supérieur.

(C) De Boeck Supérieur. Tous droits réservés pour tous pays.

La reproduction ou représentation de cet article, notamment par photocopie, n'est autorisée que dans les limites des conditions générales d'utilisation du site ou, le cas échéant, des conditions générales de la licence souscrite par votre établissement. Toute autre reproduction ou représentation, en tout ou partie, sous quelque forme et de quelque manière que ce soit, est interdite sauf accord préalable et écrit de l'éditeur, en dehors des cas prévus par la législation en vigueur en France. Il est précisé que son stockage dans une base de données est également interdit. 


\title{
Des émeutes à une crise politique : les ressorts de la politisation des mobilisations en Algérie en 1988
}

\author{
Myriam Aїт-AoudıA
}

\begin{abstract}
Résumé - Cet article analyse, à partir du cas algérien de 1988, la transformation d'émeutes en crise politique par la politisation de mobilisations multisectorielles. Cette crise produira ensuite une libéralisation inédite du régime autoritaire. Le propos est axé sur la dimension politique et contestataire de l'événement émeutes. II montre, d'une part, que la qualification politique d'un événement, ici les émeutes, ne peut être imposée en surplomb par le chercheur - souvent à partir d'une analyse ex post. II convient plutôt d'être attentif aux luttes pour la définition légitime de l'événement, en situation, et de restituer le processus par lequel une définition tend à s'imposer à tous les protagonistes, tandis que des catégorisations concurrentes sont écartées. Cet article montre, d'autre part, que la production d'une parole politique sur l'événement n'a rien d'évident, tout comme le succès de cette interprétation politique. Les émeutiers, multitude d'individus ordinaires tenus jusque-là à l'écart de la vie publique, ouvrent certes l'espace des possibles, mais ce sont des acteurs préalablement engagés qui médiatisent leur action et imposent un sens politique contestataire à l'événement en se fondant notamment sur des ressources et des réseaux antérieurs. Les caractéristiques mêmes de l'émeute - désorganisée, sans mots d'ordre, menée par de très jeunes gens qui n'articulent aucune parole politique - autorisent l'imposition, de l'extérieur, d'une parole politique consistante.
\end{abstract}


$\mathrm{L}$ e 5 octobre 1988, des émeutes éclatent à Alger et s'étendent rapidement à plusieurs villes du nord du pays ${ }^{1}$. L'état de siège est décrété, la répression militaire est particulièrement violente : des centaines d'émeutiers sont tués. Dans les semaines qui suivent, les mobilisations concomitantes de divers groupes (imams, avocats, enseignants, étudiants, médecins, journalistes, militants des droits de l'homme, etc.) qui dénoncent la répression, puis leur capacité à imposer un sens politique et contestataire aux émeutes, amèneront le pouvoir exécutif à entreprendre une libéralisation inédite du régime de parti unique - qui aboutira selon un processus complexe à l'instauration du pluralisme partisan à l'été 1989 après plus de vingt-cinq ans de monopole politique. Notre cas peut être mis en regard avec la notion de " protagonisme » proposée par Haim Burstin ${ }^{2}$ en tant qu'elle permet d'interroger les ressorts de la parole politique dans et sur l'événement. H. Burstin relève un élargissement inédit de la participation politique dans les moments révolutionnaires. Celui-ci se manifeste par de nombreuses mobilisations d'individus ordinaires, les « protagonistes ", tenus jusque-là hors de la sphère publique. L'auteur prend pour objet l'intensité narrative produite par les protagonistes, autrement dit les interventions qui qualifient tant leur propre engagement que la crise politique ellemême. Le cas algérien de l'automne 1988 permet de compléter la notion. Si les émeutiers, jeunes gens issus des quartiers populaires, ouvrent bien la séquence et pèsent sur le cours des événements du fait de leur action, l'absence, dans leurs rangs, de parole politique publiquement articulée les distingue des «protagonistes » revendiqués qu'examine $\mathrm{H}$. Burstin à propos de la Révolution française. Ils sont plutôt l'objet silencieux de la mobilisation d'autres acteurs qui, pour beaucoup, se sont déjà engagés dans la dernière décennie. Ainsi, l'action des émeutiers, c'est-à-dire les émeutes, est interprétée dans la sphère publique par divers militants qui s'auto-instituent comme leur porte-parole. De sorte que la situation algérienne offre au regard du sociologue des crises politiques un cas de protagonisme à double détente, pourrait-on dire : l'action muette des émeutiers, dépourvue de tout " dire » et de tout " prescrire », ne transforme la configuration de pouvoir que parce que des groupes de soutien travaillent à l'amplifier en prônant une lecture politique de l'événement ; inversement, c'est bien parce que les émeutes et leur répression connaissent une ampleur inédite que les revendications des groupes de soutien, dont certaines ont déjà été portées par le passé, reçoivent la capacité de reconfigurer l'ordre politique.

La littérature académique sur l'Algérie se focalise également sur le sens politique des émeutes d'octobre 1988, mais dans une perspective qui nous apparaît

1. Je remercie les évaluateurs anonymes ainsi que les coordinateurs du dossier, Quentin Deluermoz et Boris Gobille pour leurs critiques stimulantes d'une première version de cet article.

2. Burstin (H.), Révolutionnaires. Pour une anthropologie politique de la Révolution française, Paris, Vendémiaire, 2013, et « La biographie en mode mineur : les acteurs de Varennes ou le "protagonisme" révolutionnaire ", Revue d'histoire moderne et contemporaine, 57 (1), 2010. 
contestable. À en croire de nombreux travaux, les émeutes d'octobre 1988 sont causées par la "frustration » de jeunes issus des milieux populaires dans un contexte socio-économique dégradé : jeunes, pauvres et sans avenir, les émeutiers se rebellent contre leur condition misérable et les abus de pouvoir dont ils sont victimes ${ }^{3}$. Parce qu'elles ont eu pour effet la libéralisation du régime autoritaire, les chercheurs sont unanimes pour considérer les émeutes d'octobre 1988 comme le signe de la «faillite » et de "l'illégitimité » du régime FLN ${ }^{4}$. Est ignorée ici la sociologie des mobilisations qui a pourtant montré l'absence de causalité automatique entre conditions socio-économiques et émeutes, tout comme est peu argumentée la thèse de l'illégitimité du régime comme moteur des mobilisations. Enfin, l'assignation a posteriori d'un sens politique aux émeutes essentiellement fondée sur ses effets institutionnels évacue les conflits d'interprétation qui se jouent en situation tout comme la complexité de son processus de politisation. En effet, comme c'est souvent le cas des événements marquants, ces émeutes sont prises dans un faisceau d'interprétations parfois contradictoires et évolutives ${ }^{5}$. Deux discours s'affrontent : celui des autorités institutionnelles leur dénie tout caractère politique et les réduit à du pur vandalisme ; celui des divers groupes et acteurs engagés dans le soutien aux émeutiers leur confère la dignité d'une contestation politique du régime FLN. D'un côté, la dépolitisation consiste à considérer l'événement dans une perspective exclusivement sécuritaire et à criminaliser ses participants : ses tenants tentent ici de soustraire avec force les émeutes du champ politique, de priver les émeutiers de toutes aspirations politiques auxquelles les tenants du régime se verraient contraints d'apporter des réponses institutionnelles ${ }^{6}$. De l'autre, la politisation des émeutes consiste en une qualification de l'événement en termes politiques: ici les « causes », les « objectifs » et les « effets attendus » des émeutes sont cadrés

3. «Ras-le-bol » est l'expression la plus fréquemment utilisée. Voir notamment Abada (K.), « La crise économique et la mobilisation en octobre 1988 », in Le Saout (D.), Rollinde (M.), dir., Émeutes et mouvements sociaux au Maghreb. Perspective comparée, Paris, Karthala-Institut Maghreb Europe, 1999, p. 249 ; Kapil (A.), "L'évolution du régime autoritaire en Algérie : le 5 octobre et les réformes politiques de 1988-1989 ", Annuaire de l'Afrique du Nord, tome 29, 1990, p. 514-515. Dans le même sens, voir Evans (M.), Phillips (J.), Algeria. Anger of dispossessed, New Haven, Yale University Press, 2007, p. 102-142. Notons néanmoins que certains auteurs récusent à juste titre l'établissement d'une causalité automatique entre frustration dans un contexte socio-économique dégradé et émeutes : Rachik (A.), « Sciences sociales et violence collective urbaine au Maghreb », Prologues, 16, 1999, p. 22 et suiv.

4. Par exemple : les émeutes manifesteraient « la volonté des exclus d'en finir avec un régime à la fois autoritaire et défaillant [...] [et] l'arrivée à maturité politique d'une nouvelle génération qui ne se reconnaît pas dans la formule politique des dirigeants et réclame, à travers la contestation du système en place, un accès plus juste aux mécanismes de redistribution » : Labat (S.), Les islamistes algériens, entre les urnes et le maquis, Paris, Seuil, 1995, p. 51 et suiv.

5. Sewell (W. H.) « Historical Events as Transformations of Structures: Inventing Revolution at the Bastille », Theory and Society, 25, 1996.

6. Arnaud (L.), Guionnet (C.), «Introduction. Les frontières du politique », in Arnaud (L.), Guionnet (C.), dir., Les frontières du politique. Enquête sur les processus de politisation et de dépolitisation, Presses universitaires de Rennes, 2005. 
comme éléments légitimes du champ politique institutionnel ${ }^{7}$. Cette requalification politique des émeutes finira par s'imposer à tous. Elle dessinera alors rétrospectivement la vision commune de ce qui s'est passé, vision reprise dans la littérature académique sur le mode de l'évidence. Pourtant, ce n'est qu'au terme d'un intense et conflictuel " travail de signification ${ }^{8}$ » adossé à des mobilisations nombreuses et d'une dynamique maîtrisée par aucun acteur en particulier, que les élites dirigeantes proposeront des réformes institutionnelles libérales jusqu'alors inenvisageables, actant par là la lecture politique des émeutes ${ }^{9}$. Les émeutiers n'exhibent pas leurs croyances, leurs espérances, leurs idées, comme les protagonistes de $\mathrm{H}$. Burstin le font. Celles-ci sont publicisées, interprétées et politisées par d'autres acteurs investis dans le passé dans la sphère publique. La façon dont ces acteurs, extérieurs aux émeutes, caractérisent la situation et se donnent des prises pour agir sur elle, consolidera alors progressivement le sens de l'événement.

Nous analyserons dans cet article les éléments qui nourrissent ce phénomène de politisation par intermédiation de l'événement émeutes, autrement dit ses conditions de possibilité. La violente répression et la stigmatisation par les autorités institutionnelles écrasent toute prise de parole des émeutiers eux-mêmes ; les caractéristiques des émeutes (inorganisées, non structurées, sans banderoles ni mots d'ordre, menées par de très jeunes garçons vraisemblablement non politisés) renforcent la possibilité de parler à la place des émeutiers ${ }^{10}$; cette prise de parole politique émane de nombreux acteurs préalablement politisés et issus de diverses sphères sociales qui perçoivent les émeutes comme une occasion de s'imposer dans le débat public dans un contexte autoritaire et qui mobilisent à cette fin des ressources et des réseaux militants antérieurs ${ }^{11}$.

7. Lagroye (J.), «Les processus de politisation », in Lagroye (J.), dir., La Politisation, Paris, Belin, 2003.

8. Snow (D.), «Analyse de cadres et mouvements sociaux », in Céfaï (D.), Trom (D.), dir., « Les formes de l'action collective ", Raisons pratiques, 12, 2001.

9. S'agissant du monde arabe, la dimension politique des émeutes est le plus souvent considérée comme évidente et seules leurs causes et leurs effets méritent l'attention du chercheur : Sadiki (L.), « Popular Uprisings and Arab Democratization ", International Journal of Middle East Studies, 32 (1), 2000.

10. Cette particularité des émeutes est soulignée par Lagrange (H.), "Autopsie d'une vague d'émeutes ", in Lagrange (H.), Oberti (M.), dir., Émeutes urbaines et protestations. Une singularité française, Paris, Presses de Sciences Po, 2006.

11. Le matériau rassemblé pour cet article est issu de notre recherche de thèse (publiée sous le titre : L'expérience démocratique en Algérie (1988-1992). Apprentissages politiques et changement de régime, Paris, Presses de Sciences Po, 2015). Il se compose de diverses sources : des entretiens menés entre 2001 et 2006 avec des acteurs qui ont initié ou participé aux nombreuses actions collectives qui se tiennent pendant et au lendemain des émeutes (imams, militants berbéristes, médecins, étudiants, enseignants, journalistes, responsables du parti communiste algérien et des ligues des droits de l'homme) et des responsables des institutions politiques et militaires ; le dépouillement de quotidiens et périodiques algériens (El Moudjahid, Horizon, Algérie-Actualité) et français (Le Monde, Libération, L'Humanité) ; les biographies d'acteurs des mobilisations ainsi que des compilations de témoignages dans divers types de publications cités dans le texte et un film documentaire (Malik Aït-Aoudia et Séverine Labat, Algérie 1988-2003. Autopsie d'une tragédie, partie 1, Compagnie des Phares et Balises, France 3, France 5, 2003). Les entretiens ayant été répétés, leur date n'est pas précisée à chaque citation, voir les Annexes de notre livre pour le détail des dates. 


\section{Répression et disqualification des émeutiers}

\section{Déroulement et répression des émeutes}

Dans la nuit du 4 octobre 1988, plusieurs incidents éclatent à Bab-El-Oued, quartier populaire d'Alger ${ }^{12}$. Des adolescents brûlent des voitures et lancent des pierres sur des magasins. Dès le lendemain matin, les troubles s'étendent. Des jeunes saccagent des bâtiments publics, ceux des ministères de la Jeunesse et des Sports, de l'Éducation et des Transports, les locaux municipaux et départementaux du FLN et quelques commissariats. Des voitures et des bus sont renversés et incendiés ; un centre de la Loterie nationale, des sièges de compagnies aériennes, des pharmacies, des dépôts d'alimentation, des souk el fellah (supermarchés d'État), des boutiques chics et des bars de la rue Didouche-Mourad (rue commerçante du centre d'Alger) et du luxueux centre culturel et commercial Ryad el Feth sont pillés. Les manifestants envahissent plusieurs universités et lycées algérois. Ils prennent rapidement le contrôle de certains quartiers. Ils y organisent des barrages et procèdent à des contrôles d'identité. Ces actions particulièrement impressionnantes provoquent la fermeture, dès l'après-midi du 5 octobre, des établissements scolaires, des administrations, et de nombreux commerces ${ }^{13}$. Mais presque aucune violence physique contre les personnes n'est recensée. Ici et là, quelques émeutiers se moquent de certains dirigeants, essentiellement du président de la République, Chadli Bendjedid, et du premier responsable du FLN, Mohamed Chérif Messaadia ${ }^{14}$, ce qui pose une critique, toutefois désarticulée et sporadique, du pouvoir. Ainsi, à Alger, des ânes peinturlurés représentant le chef de l'État et sa femme ont été brandis par de jeunes gens arpentant la ville ; et on a entendu : "Ali Baba oui, les quarante voleurs non ${ }^{15}$ »- épisodes qui ont pu donner quelques prises aux mobilisations politiques de soutien aux émeutiers. Les émeutes s'étendent aux grands centres urbains du Nord du pays et touchent également quelques petites villes mais moins intensément. Partout, les scènes sont identiques : saccages d'établissements publics, pillages de magasins, contrôle de certains quartiers par les manifestants, et assez rapidement, répression policière et militaire.

En l'absence d'enquête précise, une sociologie des participants aux émeutes ne peut être qu'approximative, mais le recoupement de diverses sources fournit

12. La brève description qui suit concerne essentiellement les émeutes qui se déroulent dans la capitale. Outre les sources citées plus haut (entretiens, presse), elle se fonde sur les ouvrages suivants : Charef (A.), Algérie 88, un chahut de gamins ? Octobre, Alger, Laphomic, 1990, p. 84-121 ; Radio-Beur, Octobre à Alger, Paris, Seuil, 1988, p. 32-55 ; Semiane (S.-A.), dir., Octobre, ils parlent, Alger, Le Matin Éditions, 1998, p. 21-28; ainsi que du documentaire télévisé : M. Aït-Aoudia et S. Labat, Algérie 1988-2003. Autopsie d’une tragédie, cité.

13. El Moudjahid, 7-8 octobre 1988.

14. Khadda (N), Gadant (M.), « Mots et gestes de la révolte », Peuples méditerranéens, 52-53, 1990.

15. Ibid. 
néanmoins quelques informations ${ }^{16}$. Les émeutiers sont essentiellement de jeunes garçons âgés de 12 à 20 ans, lycéens, collégiens, chômeurs et hittistes ( « ceux qui tiennent le mur »). Ils habitent les quartiers défavorisés de la capitale et sont issus des classes populaires ${ }^{17}$. Il est impossible de distinguer étudiants, lycéens et jeunes chômeurs. Aucun groupe social particulier ne se donne à voir ni à entendre en tant que tel, aucune revendication catégorielle ne s'exprime. Selon l'enquête d'Abed Charef, ces jeunes n'ont aucun lien avec l'Union nationale de la jeunesse algérienne (UNJA) ${ }^{18}$, le FLN, la mouvance « islamiste » ou encore le Parti de l'avant-garde socialiste (PAGS) ${ }^{19}$. Des jeunes politiquement inorganisés, sans la médiation d'organisation sociale ou politique, contrôlent donc la rue pendant plusieurs jours. La répression militaire sera violente.

Dès le soir du 5 octobre, premier jour des émeutes, l'état de siège, qui accorde à l'armée le contrôle des pouvoirs administratifs et de sécurité, est décrété par le président de la République ${ }^{20}$. Un couvre-feu est instauré et le commandement militaire interdit immédiatement les attroupements ${ }^{21}$. L'ampleur des émeutes, l'absence de police anti-émeute, le manque d'effectifs et de matériel autour de la capitale rendent la situation ingérable pour la seule police. El Hadi Khediri, ministre de l'Intérieur, se souvient que « la police était dépassée, cela justifiait l'intervention de l'armée » (entretien). Le président fait appel au général Khaled Nezzar, commandant des forces terrestres et chef d'état-major adjoint, pour quadriller la capitale, ce qui n'est pas aisé, notamment du fait de l'éloignement des unités (entretien avec K. Nezzar). L'ampleur des moyens mobilisés montre que la situation est jugée alarmante. Pour la première fois depuis la tentative de coup d'État contre le président Boumediene par Tahar Zbiri en décembre 1967, les chars entrent dans la capitale ${ }^{22}$. À partir du 6 octobre, l'armée contrôle les grands axes stratégiques de la ville. Les premiers affrontements éclatent. Alors que le 9 octobre, le journal El Moudjahid titre « Retour au calme progressif à Alger ", la répression dans la capitale est à son paroxysme. À l'exception d'Oran ${ }^{23}$, aucune ville ne connait le niveau de violence observé à Alger.

16. La littérature sur les émeutes montre la difficulté à rassembler ce type d'informations. S’agissant de la France, des chercheurs proposent une sociologie des participants fondée sur des archives judiciaires et policières est proposée par Lagrange (H.), « Autopsie d'une vague d'émeutes », art. cit.

17. On reconnaît ici les traits distinctifs de l'émeute : « action collective spontanée, illégale qui recruterait en bas de l'échelle sociale », cf. Le Saout (D.), « Introduction », in Le Saout (D.), Rollinde (M.), dir., Émeutes et mouvements sociaux au Maghreb..., op. cit., p. 12.

18. Organisation de masse organiquement liée au FLN.

19. Le PAGS, crée en 1966, est l’héritier du Parti communiste algérien. Il est « toléré » par le régime et pratique ce que sa direction appelle « une politique de soutien critique » à l'endroit du régime.

20. Communiqué de la présidence de la République, El Moudjahid, 7-8 octobre 1988.

21. Communiqué ${ }^{\circ} 1$ du commandement militaire, El Moudjahid, 7-8 octobre 1988.

22. Cela avait été également le cas lors du coup d'État de H. Boumediene contre le président Ben Bella, le 19 juin 1965. En 1988, c'est la première fois que les militaires utilisent la force contre la population civile.

23. Le Monde, 9-10 octobre 1988. L'armée prend position à Oran, bien que l'état de siège ne soit officiellement instauré que dans l'Algérois. 
Pendant les émeutes, aucune information ne filtre sur le nombre de blessés et de morts, mais des coups de feu retentissent fréquemment dans les rues de la capitale. Le 7 octobre, les services de sécurité annoncent « l'arrestation de neuf cents personnes prises en flagrant délit de pillage et de vandalisme à l'encontre de biens publics et privés ${ }^{24} »$. Des rumeurs se répandent sur la torture que subissent les jeunes émeutiers arrêtés. La Ligue algérienne des droits de l'homme (LADH) publiera un rapport accablant selon lequel « la torture a été pratiquée à grande échelle. [...] Les auteurs de tirs ont parfois agi avec une volonté délibérée de tuer. [...] Les forces de l'ordre ont utilisé des balles explosives ${ }^{25}$. » Le bilan officiel est de " cent cinquante-neuf morts dont cinq éléments des services de sécurité, cent cinquante-quatre blessés et cent soixante et un milliards de centimes de dégâts occasionnés aux édifices publics et aux biens publics et privés ${ }^{26} »$. Mais les milieux hospitaliers et diverses associations dénombrent cinq cents morts ${ }^{27}$. Le 10 octobre sera la dernière journée des émeutes et la plus sanglante : plusieurs dizaines de civils sont tués en quelques minutes.

\section{La disqualification politique des émeutiers}

Dans la soirée du 5 octobre, la section départementale du FLN d'Alger appelle ses militants à rejoindre leurs sections locales, afin de les protéger des attaques des émeutiers. Hormis cette initiative, les responsables du parti unique restent discrets dans les premiers jours. Le bureau politique (BP) du FLN, qui se réunit pourtant le 5 et le 9 octobre, ne fait aucune déclaration. Dans la soirée du 8, après quatre jours de violence, El Hadi Khediri, ministre de l'Intérieur, intervient à la télévision pour dénoncer « la destruction des écoles, lycées, laboratoires, biens publics construits à la sueur de notre front avec nos enfants et pour nos enfants", et désigne sans plus de précision " des éléments perturbateurs $^{28} »$. Le même jour, le ministère de la Justice souligne : "Les fauteurs de troubles graves ayant commis des destructions de biens publics et privés, et porté atteinte à l'intégrité physique des citoyens et du symbole même du patrimoine national, seront jugés par les tribunaux statuant en audition spéciale ${ }^{29}$. Le commandement militaire dénonce de la même façon « les jeunes manipulés par les ennemis du peuple algérien et de sa révolution qui ont saccagé des édifices publics, pillé des biens publics et privés, violé des domiciles et porté atteinte aux symboles mêmes du patrimoine national ${ }^{30}$ ». Les jeunes émeutiers sont assimilés à des voyous dénués de toute conscience politique, manipulés et dirigés contre l'État et la population. Les moyens mis en œuvre sont à la

\footnotetext{
24. El Moudjahid, 7-8 octobre 1988.

25. Le rapport est rendu public le 19 novembre. Voir Algérie-Actualité, 14-21 novembre 1988.

26. El Moudjahid, 21-22 octobre 1988.

27. Comité national contre la torture, Cahier noir d'octobre, Alger, Éditions ENAG, 1988 ; Conférence de presse de $\mathrm{M}^{\mathrm{e}}$ Miloud Brahimi, président de la LADH, le 13 octobre, L'Humanité, 14 octobre 1988.

28. El Moudjahid, 10 octobre 1988.

29. El Moudjahid, 9 octobre 1988.

30. Communiqué du commandement militaire, El Moudjahid, 7-8 octobre 1988.
} 
mesure du forfait : «La protection des édifices publics et des biens sera assurée au besoin par la force, y compris par l'usage des armes après les sommations d'usage $^{31}$. » La très officielle Union générale des travailleurs algériens (UGTA) accuse « les ennemis internes de la Révolution ${ }^{32}$ ». Certains journalistes participent à cette vaste entreprise de stigmatisation des émeutiers : El Moudjahid fustige « les troupes de jeunes qui envahissent les bâtiments publics [...], et les actes de barbarie et de vandalisme de ces voyous ${ }^{33} »$. Comme c'est souvent le cas lors de violences urbaines, les jeunes sont disqualifiés et criminalisés ${ }^{34}$ par les autorités civiles et militaires ainsi que dans certains médias. Simple rassemblement de «voyous » ou «chahut de gamins qui a dérapé 35 », l'événement n'appelle aucune autre réponse que la répression.

Au même moment apparaît une version très différente de ce qu'il est en train de se passer. Des individus issus de diverses sphères sociales organisent de nombreuses actions collectives de soutien aux émeutiers : manifestations de rue, distributions de tracts, animation de réunions publiques ou adresses de « lettres ouvertes » au président. Ces diverses actions se caractérisent par leur simultanéité et par une certaine homogénéité de leur propos. Les échos qu'elles trouvent dans une partie de la presse témoignent d'une libéralisation de la parole jusqu'alors inconnue : on y dénonce la répression des jeunes manifestants ainsi que le caractère autoritaire et défaillant du régime, ce qui contribue à la politisation des émeutes. Considérées non plus comme du "vandalisme de voyous manipulés ", mais comme une "révolte sociale et politique des jeunes victimes du système FLN », elles appellent ici des solutions politiques et non policières. C'est tout le diagnostic de la situation ${ }^{36}$ qui se trouve alors inversé, ouvrant la voie à des solutions politiques inédites. Les islamistes méritent ici une attention particulière car ils sont les plus nombreux et ils s'engagent dans les actions les plus visibles, bien que la politisation des émeutes urbaines soit redevable d'un cadrage engageant une vaste palette d'acteurs.

\section{La politisation des émeutes par les mobilisations islamistes}

Il a été souvent écrit que les islamistes se sont rapidement approprié ce mouvement ${ }^{37}$. Il apparaît plutôt que les islamistes ne forment pas une entité

31. Ibid.

32. El Moudjahid, 9 octobre 1988.

33. El Moudjahid, 10 octobre 1988.

34. Mauger (G.), L'Émeute de novembre 2005. Une révolte protopolitique, Bellecombe-en-Bauges, Éditions du Croquant, 2006, p. 85-96.

35. Selon l'expression d'Ali Ammar, président de l'Amicale des Algériens en Europe liée au FLN, le 7 octobre 1988, Radio-Beur, Octobre à Alger, op. cit., p. 124-126.

36. Benford (R. D.) et Snow (D. A.), " Processus de cadrage et mouvements sociaux : présentation et bilan », Politix, 99 (3), 2012.

37. Voir notamment Quandt (W. B.), Société et pouvoir en Algérie. La décennie des ruptures, Alger, Casbah Éditions, 1999 [1998], p. 57 ; Lavenue (J.-J.), Algérie, La démocratie interdite, Paris, L’Harmattan, 1993, p. 12. 
homogène ayant une vision claire de la stratégie à mener à propos des émeutes. Cette nébuleuse est traversée de tensions qui se manifestent clairement durant cet épisode et la plupart des imams impliqués improvisent et hésitent quant à la marche à suivre.

\section{Dénonciation de la répression et appels au calme}

Dès le déclenchement des émeutes, plusieurs imams prennent des initiatives. Elles sont d'abord ponctuelles, individuelles et locales. Dans les quartiers les plus touchés, ils se rencontrent au gré des affinités personnelles et des sensibilités religieuses pour commenter les événements et lancer depuis leur mosquée des appels au calme et à la vigilance. Azzedine, prédicateur à Bab-El-Oued, rapporte ainsi : « Nous [avons] appelé les gens à rester calmes, à ne pas répondre aux provocations. La situation était vraiment très tendue. Notre rôle en tant qu'imams, c'était d'apaiser les tensions, de dire aux gens de rester chez eux, de les prévenir qu'il y avait partout des voitures qui tiraient à balles réelles. » (Entretien.)

Le type d'implication des imams dépend de leur proximité avec les autorités locales et de l'ampleur de la répression dans leur quartier. Les "imams d'État ${ }^{38}$ » sont directement sollicités par des responsables régionaux et locaux du FLN pour contenir les protestations ${ }^{39}$. Un rassemblement a lieu le vendredi 7 octobre, jour de la grande prière. Des foules se massent dans et autour des mosquées pour écouter les premiers prêches depuis le déclenchement des émeutes. À Alger, les forces de sécurité sont postées devant les mosquées dans lesquelles officient des « imams libres » populaires, tels Ahmed Sahnoun, pionnier de l'islamisme algérien contemporain ${ }^{40}$ installé dans le quartier de Chevalley ou Ali Benhadj, jeune militant contestataire à Bab-El-Oued ${ }^{41}$.

38. Contrairement aux imams libres qui sont seulement " tolérés », les imams fonctionnaires sont rétribués par l'État et leurs prêches sont encadrés par le ministère des Affaires religieuses. Ils constituent souvent des relais des politiques gouvernementales.

39. Entretien avec Aïssa Kassa, responsable départemental du FLN à M'Sila.

40. Né en 1906, Ahmed Sahnoun est un membre influent de l'association des oulémas dès sa création en 1931. Il dirige dans les années 1950 la section algérienne des Frères musulmans et sera emprisonné pendant la guerre de libération. À l'indépendance, il fonde avec d'autres prédicateurs l'association islamique El Qiyam (les valeurs) qui sera interdite en 1966. Après avoir occupé des fonctions liées au ministère des Affaires religieuses, Ahmed Sahnoun se distinguera par ses critiques du socialisme étatique. Il co-organise la première manifestation islamiste le 12 novembre 1982 et cosigne avec Abassi Madani et Abdelatif Soltani (décédé en 1984) une plate-forme de revendications qui exige une moralisation de la vie publique fondée sur une application stricte de la religion. Il sera arrêté, puis assigné à résidence jusqu'en 1984. Il contribue à la formation religieuse et politique de nombreux prédicateurs (l'année 1988 borne chronologiquement cette notice biographique).

41. Né en 1956, cet enseignant d'arabe s'est illustré, depuis le début des années 1980, par diverses actions de contestation du régime qui ont conduit à plusieurs arrestations. Il débute sa carrière de prédicateur libre dans une mosquée d'El Achour, fief de Mustapha Bouyali, fondateur du Mouvement islamique armé, qu'il soutient par plusieurs fatwas. Dans ce cadre, il sera arrêté pour " atteinte à la sûreté de l'État " et condamné en 1985 à trois ans de prison. Après une grâce présidentielle, il est assigné à résidence jusqu'en 1987. Depuis, ses prêches bénéficient d'une large audience (l'année 1988 borne chronologiquement cette notice biographique). 
Au sortir de la prière, quelques milliers de fidèles marchent ensemble du quartier de Belcourt vers l'hôpital Mustapha Bacha pour exiger la remise des corps des victimes entreposés à la morgue. Ali Benhadj déclare ensuite avoir vu « les corps de jeunes de treize et quatorze ans, tués par balles, que les autorités ne veulent pas rendre à leurs parents ». Il appelle les " fidèles à donner leur sang pour les blessés ${ }^{42} »$. Quelques manifestants scandent des slogans religieux, comme "La Ilahailla Allah» (Il n’y a de Dieu que Dieu) tout en dénonçant la répression. Les manifestants font face à un important dispositif de sécurité et se séparent dans le calme.

\section{Une tentative de mobilisation islamiste}

Après le rassemblement du 7 octobre, certains imams libres, qui comptent parmi les plus engagés dans la da'wa (proclamation de la foi ${ }^{43}$ ) envisagent d'autres actions. Les 9 et 10 octobre, un tract anonyme, attribué à Ali Benhadj ${ }^{44}$, est diffusé dans les mosquées d'Alger. Il appelle à une marche de protestation " contre la répression et pour la défense de l'islam ${ }^{45}$ ». Loin d'émaner d'un projet défini collectivement, l'initiative d'Ali Benhadj relève surtout d'une volonté de se démarquer des imams fonctionnaires et de se positionner comme figure centrale de la da'wa. Toutefois, même s'il jouit d'un prestige certain, notamment en raison de son séjour en prison, sa jeunesse (il a 32 ans) le pousse à obtenir l'aval des anciens. Certains prédicateurs s'opposent à toute marche, comme Ahmed Sahnoun qui diffuse un tract dans lequel il dénonce cette initiative "inconséquente ${ }^{46}$ ». Dans la matinée du 10 octobre, il lance publiquement devant une mosquée d'Alger un "appel au calme » destiné à contrer le projet du jeune imam ${ }^{47}$. Ce jour-là verra l'organisation d'une action collective labellisée "islamiste ${ }^{48}$ ». L'opportunité d'une telle manifestation suscite de fortes oppositions et son déroulement même

\footnotetext{
42. Le Monde, 9-10 octobre 1988.

43. La da'wa recouvre un vaste ensemble d'activités hétérogènes qui dépasse l'action des imams : prêches, diffusion d'ouvrages ou de cassettes, prosélytisme de proximité dans les quartiers, actions sociales, etc.

44. Cette information est issue de plusieurs sources (entretiens et ouvrages).

45. Harichane (A.), Le FIS et le pouvoir, Alger, Éditions LallaSakina, 2001, p. 17 et suiv.

46. Khalladi (A.), Les islamistes algériens face au pouvoir, Alger, Éditions Alpha, 1992, p. 95.

47. Entretien avec Ahmed Sahnoun par Boudjenoun (M.), Les années fastes et néfastes de l'islamisme algérien, Alger, Auto-édition, 2000, p. 53-56.

48. Elle sera définie comme "islamiste " tant par les organisateurs que par les médias ou les autres acteurs qui se mobiliseront dans les semaines qui suivent. Précisons que l'usage du terme " islamiste » ne renvoie pas ici à une catégorie que je distingue de l'" intégrisme » ou du " fondamentalisme » sur la base du rapport à l'État, comme le propose par exemple Roy (O.), "Fondamentalisme, intégrisme, islamisme ", Esprit, 100 (1), 1985 ; "Le néofondamentalisme : des Frères musulmans au FIS algérien », Esprit, 180 (3-4), 1992. L'attribution de ces labels constitue un enjeu politique autant que scientifique : il n'est donc pas possible de donner une définition substantialiste de l'islamisme. Les acteurs qui nous intéressent ici sont ceux qui s’identifient eux-mêmes comme "islamistes » (en français ou en arabe) et sont identifiés comme tels par les autres protagonistes, sans que la dimension politique fasse l'objet d'une acception commune.
} 
reste très confus. Hachemi Sahnouni, imam libre, compagnon de route d'Ali Benhadj, en témoigne :

«Ali Benhadj et moi l'avons organisée. En fait, ce n'était pas vraiment une marche. Nous voulions organiser un rassemblement à Belcourt près de la mosquée Salah Edine El Eyoubi et présenter des doléances aux autorités. Nous ne pensions pas vraiment faire une marche, puisqu'il y avait l'état de siège et les marches étaient donc interdites. Si nous avions organisé une marche, ils nous auraient tirés dessus. On le savait. [...] Benhadj était absent ce jour-là, il n'était pas venu car tous les chouyoukhs [les « religieux sages »] étaient contre cette idée. » (Entretien avec H. Sahnouni)

On le voit, les hésitations, les divergences et la répression compromettent la possibilité même de qualifier la nature de cet événement : " manifestation », " rassemblement ", " marche », " simple retour collectif à la maison après la prière », comme certains l'ont précisé ${ }^{49}$ ? Certes, cette impressionnante foule d'individus se déplaçant dans la même direction et scandant des slogans ressemble à une manifestation, même s'il est possible que cette ampleur soit due à l'afflux des fidèles sortant des mosquées. Certains prédicateurs et leaders islamistes imputent à Ali Benhadj la responsabilité de la mort des trente personnes tuées ce jour-là ${ }^{50}$. Les conflits entre les principaux prédicateurs témoignent à la fois de l'hétérogénéité des islamistes et du degré d'improvisation dans la gestion des émeutes, loin de l'image d'un groupe structuré encadrant les émeutiers. Les initiatives prennent corps dans et autour des mosquées. Elles rassemblent à chaque fois des centaines, voire des milliers d'individus. Elles se tiennent malgré l'interdiction des rassemblements pendant l'état de siège. Le général Khaled Nezzar, responsable du maintien de l'ordre, tout comme El Hadi Khediri, ministre de l'Intérieur, nient avoir autorisé ces rassemblements ${ }^{51}$. Officiellement, aucun responsable de l'État ne mentionnera cette journée sanglante.

\section{Les solutions politiques islamistes à la crise d'octobre}

Au cours de cet épisode, des solutions politiques à la crise qui frappent par leur similarité sont proposées par différents acteurs des milieux islamistes. Leurs auteurs, les principaux imams d'Alger, s'attachent à relever les causes des émeutes et revendiquent des réponses précises de la part du régime, les inscrivant résolument dans le registre politique. La dimension religieuse constituera ici la principale voie de sortie de ce qui est perçu comme une crise extrêmement grave. Ahmed Sahnoun affirme que les émeutes sont issues

\footnotetext{
49. Entretien avec Mohamed Bouyali, ancien membre du Mouvement islamique armé (MIA), premier groupe terroriste créé en 1982 par son frère.

50. Mohamed Saïd, bras droit d'Ahmed Sahnoun, le reprochera publiquement à Ali Benhadj.

51. Témoignage d'El Hadi Khediri dans Sémiane (S.-A.), dir., Octobre, ils parlent, Alger, Le Matin Éditions, 1999, p. 104 ; entretien avec K. Nezzar.
} 
d'une crise qui trouve « ses motifs et ses raisons dans une situation générale dégradée par la faute d'une politique de prestige, de luxe et de gaspillage au détriment des intérêts suprêmes de la nation ${ }^{52}$ ", et que la solution consiste en "l'instauration d'une société basée sur l'islam" ${ }^{53}$ ». Quant à Mahfoud Nahnah ${ }^{54}$, il diffuse un tract dans lequel il attribue aux gouvernements successifs depuis l'indépendance la responsabilité des événements tragiques de la semaine du 5 octobre : il y dénonce " la dépravation politique et les luttes internes aux appareils d'État ${ }^{55} »$. Pour les deux leaders islamistes, les émeutes sont une réaction légitime face à un État incapable de satisfaire la population. Le 6 octobre, un tract rédigé par Ahmed Sahnoun circule dans les mosquées de la capitale. Il affirme la nécessité de l'application de la «choura [consultation] [...], la pureté des mœurs, la justice dans la répartition des richesses nationales entre les différentes couches du peuple ${ }^{56} »$. Une semaine plus tard, il énonce une série de revendications plus précises : " une amnistie générale au profit des détenus d'opinion, la garantie de la liberté de prédication et l'immunité aux imams, [...] la garantie des libertés politiques, la remise de la parole au peuple ${ }^{57} »$. Les revendications s'adressent aux représentants de l'État. À ces communiqués s'ajoutent les interventions d'Ali Benhadj. Le vendredi 14 octobre 1988, lors d'un prêche à la mosquée Sunna, le jeune imam fait un réquisitoire. Il exige « la fin de l'état de siège qui prévaut depuis l'indépendance du pays ; l'amnistie de tous les détenus politiques et d'opinion et pas uniquement ceux arrêtés durant les émeutes; la fin du népotisme et des féodalités politiques et administratives ; la garantie d'un minimum vital pour chaque Algérien ; la liberté de propager l'islam sans aucune restriction ; la liberté fondamentale pour le peuple de disposer de ses propres affaires [...] ; la réforme de l'éducation, afin de promouvoir un enseignement islamique, d'élever la sensibilité islamique des étudiants et de promouvoir l'esprit collectif, etc. ${ }^{58} \gg$ Ali Benhadj se fait plus précis : les émeutes signent l'échec du régime en matière d'éducation, de culture, de religion, de politique, de justice et d'administration.

52. Cité par Laba (S.), Les islamistes algériens... op. cit., p. 52.

53. Tract daté du 28 octobre, cité par Layachi (H.), Les islamistes algériens entre le pouvoir et les armes (en arabe), Alger, Dar Al Hikma, 1992, p. 273.

54. Né en 1942, Mahfoud Nahnah se réclame des Frères musulmans. Dans les années 1960, il dirige la prière du vendredi à la nouvelle mosquée universitaire d'Alger. Il est condamné à quinze ans de prison pour son opposition au projet socialiste. Il sera gracié par le président Chadli après quatre ans. Son passage en prison lui vaut une solide réputation. Il refuse par ailleurs de soutenir le Mouvement islamique armé et suscite depuis la méfiance des prédicateurs proches de Mustapha Bouyali et d'Ali Benhadj (l'année 1988 borne chronologiquement cette notice biographique).

55. Tract daté du 13 octobre 1988, cité par Layachi (H.), Les islamistes algériens..., op. cit., p. 266.

56. Cité dans Benarros (Z.), Aït-Idir (A.), Midjek (F.), L’Islamisme politique : la tragédie algérienne, Beyrouth,

Dar Al Farabi, 2002, p. 76-81.

57. Ibid., p. 77-78.

58. Charef (A.), Algérie 88, un chahut de gamins ?, op. cit., p. 117-118. 
Les imams engagés proposent ainsi des réformes structurelles qui dépassent leurs discours initiaux de dénonciation de la répression. En dépit des incertitudes et des divergences stratégiques entre les imams, la similarité des discours est patente. La "requalification politique ${ }^{59}$ » des émeutes par les principaux leaders islamistes repose sur une demande de refonte générale d'un régime jugé inique. Un retour sur d'anciens épisodes contestataires organisés par ces mêmes imams permet de mettre au jour une réactivation de la parole politique. En effet, à l'occasion des émeutes d'octobre 1988, ils réitèrent des revendications plus anciennes, notamment celles promues lors du grand rassemblement du 12 novembre 1982 organisé par les figures populaires engagées dans la da'wa, à savoir Ahmed Sahnoun, Abdellatif Soltani et Abassi Madani. Si le point de départ de la manifestation a été la demande de réouverture des mosquées universitaires fermées après l'assassinat d'un étudiant trotskiste par un islamiste sur le campus de Ben Aknoun, la liste des doléances en quatorze points adressées au président de la République et lues devant un auditoire de plusieurs milliers de personnes incluaient des revendications plus larges, principalement axées sur la moralisation de la vie publique : étaient ainsi dénoncées la «dépravation », la "mixité [comme] indice alarmant du déclin moral » ou encore les « manifestations [culturelles] bouffonnes et irrévérencieuses », comme les concerts. Était ainsi pointée en 1982 la crise des valeurs dont ces différents signes témoignaient et qui ne pouvait être résolue que " [dans] le cadre d'un sincère retour à l'islam ${ }^{60}$ ". À l'automne 1988, à ces thématiques de la moralisation de la vie publique et du renforcement de l'islam dans la société s'ajoutent donc des revendications plus précises sur la libéralisation du régime. Relevons néanmoins que personne ne réclame l'instauration du pluralisme partisan. En somme, chacun des imams tente de se faire le porte-parole d'émeutiers qui n'expriment aucune revendication politique unifiée, s'appuyant par là notamment sur le cour de leur engagement préalable dans un contexte de concurrence dans la sphère religieuse.

\section{Mobilisations multisectorielles et succès de la politisation des émeutes}

Un recadrage politique des émeutes s'opère simultanément dans la constellation de collectifs qui manifestent publiquement leur soutien aux émeutiers : médecins, avocats, journalistes, universitaires, étudiants, intellectuels, anciennes combattantes de la guerre de libération, berbéristes, militants

\footnotetext{
59. Lagroye (J.), « Les processus de politisation », art. cit, p. 367.

60. Le texte est publié dans Al-Ahnaf (M.), Botiveau (B.) et Frégosi (F.), L’Algérie par ses islamistes, Paris, Karthala, 1991, p. 45-48. L'appel du 12 novembre 1982 ne constitue pas un programme « révolutionnaire " et s'intègre dans le cadre du régime existant. Pourtant, le pouvoir lui accordera une dimension contestataire puisque trente-six personnes seront arrêtées.
} 
des droits de l'homme, membres du parti communiste algérien (PAGS), anciennes personnalités politiques comme le premier président algérien Ahmed Ben Bella ou le fondateur du FFS, Hocine Aït-Ahmed, ou encore le " groupe des dix-huit » (comptant des anciens dirigeants de la présidence de H. Boumediene). À l'exception notable d'Abed Charef ${ }^{61}$, les travaux se concentrent sur les mobilisations islamistes, probablement parce que les islamistes deviennent dans les mois qui suivent le principal acteur politique de la transition démocratique. L'« oubli » des autres acteurs mobilisés s'explique probablement par le fait qu'ils n'auront pas plus tard le même succès. Pourtant, sur le moment, ces "mobilisations multisectorielles ${ }^{62}$ », inédites dans l'Algérie post-indépendance, sont au cœur du processus de politisation des émeutes qui va progressivement s'imposer à tous, y compris aux élites institutionnelles et militaires. Elles sont le signe de l'émergence d'une crise politique. Chronologiquement, elles se déploieront davantage après la journée sanglante du 10 octobre qui met un terme aux émeutes et qui ralentit considérablement les engagements islamistes. En somme, les deux processus sont parallèles et convergeront partiellement.

\section{Multiplication, concomitance et médiatisation des mobilisations}

Ces actions de protestation prennent diverses formes - du communiqué de presse à la manifestation de rue, de la pétition à l'assemblée générale, de la lettre ouverte à la grève de la faim, du sit-in à la publication de rapports d'expertise et se concentrent dans la période du 6 octobre à mi-novembre 1988.

Ces actions ont toutes pour point de départ les émeutes. Hormis les déclarations d'Ahmed Ben Bella et de Hocine Aït-Ahmed, en exil depuis de nombreuses années, elles se déroulent essentiellement à Alger et dans une moindre mesure à Tizi-Ouzou. Leur concentration dans la capitale, leur ampleur et leur simultanéité contribuent à leur visibilité. Certaines sont organisées pendant les troubles (A. Ben Bella et H. Ait-Ahmed s'expriment dès le 6 octobre, les journalistes se mobilisent à partir du 9, le PAGS se manifeste le 5) et se poursuivent tout au long du mois d'octobre. D'autres, comme celles des médecins, des deux ligues des droits de l'homme, des avocats, du " groupe des dix-huit ", des universitaires, des étudiants, des intellectuels et des moudjahidates, débutent mi-octobre. La presse écrite, les télévisions et les radios algériennes et étrangères les relayent abondamment. Cette médiatisation propulse les actions de protestation sur la scène publique nationale et internationale, compensant ainsi leur relative faiblesse numérique (elles ne rassemblent à chaque fois que quelques dizaines ou centaines de personnes).

61. Charef (A.), Algérie 88, un chahut de gamins ?, op. cit., p. 73-120, p. 129-161 et p. 192-233.

62. Dobry (M.), Sociologie des crises politiques. La dynamique des mobilisations multisectorielles, Paris, Presses de la Fondation nationale de science politique, 1992 [1986], p. 40 et suiv. 
Malgré la répression brutale des émeutes, ces acteurs se mobilisent pour soutenir les émeutiers et dénoncer la violence. Ils ont conscience des risques, mais pour plusieurs raisons, ils estiment que leur propre sécurité sera préservée. Parlant de la grève des commerçants organisée en Kabylie par des militants berbéristes, Areski Aït-Larbi, interrogé en entretien, résume la situation. «On s'est posé la question : "On va réagir, il faut réagir, mais comment? Comment ne pas exposer les gens aux balles, tout en étant solidaires avec ce qui se passe?" [...] L'idée centrale, c'était : "Comment participer sans risque de répression ?" » En effet, les organisateurs prennent soin d'éviter toute confrontation directe avec les forces de l'ordre. La rue est très peu investie, les réunions sont organisées dans des lieux fermés et supposément protégés de toute intervention militaire ou policière (assemblées générales dans des salles de rédaction de presse ou dans des amphithéâtres, pétitions, rassemblement dans des cimetières, etc.), les pétitions, communiqués et lettres ouvertes sont privilégiés. Les très fortes critiques au sein des milieux islamistes de l'organisation d'une " marche » le 10 octobre par Ali Benhadj qui a été très violemment réprimée (une trentaine de morts) confirment la perception générale d'un danger à investir la rue face à l'armée. Cet épisode incite inévitablement les acteurs qui se mobiliseront dans les jours et les semaines qui suivent à prendre des précautions. Le faible sentiment de vulnérabilité s'explique aussi pour partie par la perception du soutien de larges couches de la population, par le prestige dont jouissent certaines personnalités engagées (avocats pendant la guerre d'indépendance, anciennes combattantes) et par leur appartenance à des couches sociales difficilement disqualifiables (médecins, avocats, universitaires). Le journaliste Ahmed Ancer raconte : «On savait que ce n'était pas la même chose que les jeunes émeutiers. [...] Même si la police a cherché à intimider certains d'entre nous, par la visite de policiers au domicile, la confiscation de passeport, etc. On savait que nous étions moins vulnérables que les jeunes. [...] Et puis, on a considéré que le danger était passé, c'était vraiment une autre atmosphère. » (Entretien.) Les acteurs mobilisés n'ont manifestement pas confiance dans les autorités politiques et militaires, ils s'en méfient, mais cette méfiance ne les empêche pas d'agir. Des précautions dans le choix des modes d'action, un fort sentiment de légitimité et une stratégie d'évitement qui repose sur leur expérience militante deviennent autant de facteurs qui libèrent l'action sans crainte d'un risque démesuré ${ }^{63}$.

63. La question de l'effet de la répression sur les mobilisations fait l'objet de nombreux débats, elle ne reçoit pas de réponse unique : Combes (H.) et Fillieule (O.), « De la répression considérée dans ses rapports à l'activité protestataire. Modèles structuraux et interactions stratégiques ", Revue française de science politique, 61 (6), 2011. 
Tableau 1. Multiplication et concomitance des mobilisations

\begin{tabular}{|c|c|c|}
\hline $\begin{array}{l}\text { Personnalités } \\
\text { et collectifs } \\
\text { mobilisés }\end{array}$ & Dates & Modes d'intervention \\
\hline Médecins ${ }^{64}$ & $\begin{array}{l}\text { - octobre } \\
-18 \text { octobre } \\
-18 \text { et } 31 \text { octobre }\end{array}$ & $\begin{array}{l}\text { - communiqués de presse } \\
\text { - assemblées générales } \\
\text { - manifestations }\end{array}$ \\
\hline $\begin{array}{l}\text { Enseignants à } \\
\text { l'université }{ }^{65}\end{array}$ & $\begin{array}{l}\text { - octobre } \\
-15,17,18,26 \text { octobre } \\
-17 \text { octobre } \\
\text { - } 24 \text { novembre }\end{array}$ & $\begin{array}{l}\text { - communiqués de presse } \\
\text { - assemblées générales } \\
\text { - création d'un Comité national contre la } \\
\text { torture } \\
\text { - rassemblement à la mémoire des victimes } \\
\text { au cimetière d'El Alia à Alger }\end{array}$ \\
\hline Étudiants ${ }^{66}$ & \begin{tabular}{|l} 
- octobre-novembre \\
- 18,26 octobre, \\
2 et 5 novembre
\end{tabular} & $\begin{array}{l}\text { - assemblées générales et sit-in dans les } \\
\text { universités algéroises (fin des émeutes) } \\
\text { - pétitions, manifestations } \\
\text { - organisation d'une grève de la faim }\end{array}$ \\
\hline Journalistes $^{67}$ & $\begin{array}{l}-9,10,24 \text { octobre } \\
-9 \text { octobre } \\
-20 \text { octobre }\end{array}$ & $\begin{array}{l}\text { - communiqués et assemblées générales } \\
\text { dans les rédactions de certains journaux } \\
\text { - réunion publique } \\
\text { - pétition, création d'une organisation profes- } \\
\text { sionnelle « autonome » et « démocratique » } \\
\text { - réunion de } 200 \text { journalistes }\end{array}$ \\
\hline Intellectuels ${ }^{68}$ & - octobre & - communiqués, lettre au président \\
\hline Avocats ${ }^{69}$ & $\begin{array}{l}\text { - octobre } \\
\text { - } 19 \text { octobre }\end{array}$ & $\begin{array}{l}\text { - lettre au président, communiqués } \\
\text { - réunion publique }\end{array}$ \\
\hline $\begin{array}{l}\text { Ligues des droits } \\
\text { de l'homme } \\
\text { - LADDH }{ }^{70}\end{array}$ & - 2 novembre 1988 & $\begin{array}{l}\text { - Ali-Yahia : Rapport sur la torture publiée } \\
\text { par la FIDH }\end{array}$ \\
\hline
\end{tabular}

64. Quelques dizaines de médecins (surtout de l'hôpital Mustapha à Alger).

65. Essentiellement à l'Université des Sciences de Bab Ezzouar et à la faculté centrale d'Alger.

66. Dans la plupart des universités de l'Algérois.

67. Plusieurs dizaines de journalistes (El Moudjahid, Algérie-Actualité, Radio Alger chaîne 3, Télévision nationale).

68. Des écrivains et cinéastes dont Anouar Benmalek, Abderrahmane Djalfaoui, etc.

69. Des avocats du prestigieux collectif en charge de la défense des militants nationalistes de la guerre d'indépendance.

70. Ligue algérienne de défense des droits de l'homme, non reconnue par l'État : des militants berbéristes, essentiellement des médecins et des avocats, pour beaucoup arrêtés à plusieurs reprises pour délits d'opinion (S. Sadi, Mokrane et Areski Aït-Larbi, S. Khelil, M. Lounaouci, etc.), déposent le 30 juin 1985, une demande d'agrément officiel de la première Ligue algérienne des droits de l'homme, demande qui sera refusée. Elle sera dirigée par $\mathrm{M}^{\mathrm{e}}$ Ali Yahia Abdenour. La plupart de ses fondateurs sont arrêtés au cours de l'été 1985 et condamnés par la cour de sûreté de l'État. Voir Collectif contre la répression en Algérie, $A u$ nom du peuple. Vous êtes accusés d'atteinte à l'autorité de l'État. Qu'avez-vous à dire?, Paris, Imedyazen, 1986, p. 11. Les derniers militants sortiront de prison en 1987. 


\begin{tabular}{|c|c|c|}
\hline - $\mathrm{LADH}^{71}$ & $\begin{array}{l}\text { - octobre-novembre } \\
-9 \text { et } 11 \text { octobre } \\
\text { - } 16 \text { novembre } \\
\text { - } 30 \text { octobre }\end{array}$ & $\begin{array}{l}\text { - communiqués de presse } \\
\text { - appels au président } \\
\text { - rapport de la Commission d'enquête } \\
\text { sur les atteintes aux droits de l'homme } \\
\text { pendant les émeutes } \\
\text { - délégation reçue par le président }\end{array}$ \\
\hline «Berbéristes ${ }^{72} »$ & $\begin{array}{l}-10 \text { au } 11 \text { octobre } \\
-9 \text { novembre } \\
-25 \text { novembre }\end{array}$ & $\begin{array}{l}\text { - grève générale de } 2 \text { jours en Kabylie } \\
\text { - diffusion de tracts } \\
\text { - déclaration publique (devant } \\
2000 \text { personnes, campus de Tizi-Ouzou) } \\
\text { - meeting à Tizi-Ouzou }\end{array}$ \\
\hline Moudjahidates ${ }^{73}$ & - 25 octobre 1988 & $\begin{array}{l}\text { - lettre ouverte au président de la } \\
\text { République }\end{array}$ \\
\hline $\begin{array}{l}\text { PAGS (parti de } \\
\text { l'avant-garde } \\
\text { socialiste) }\end{array}$ & $-5,9,10$ octobre & $\begin{array}{l}\text { - déclarations publiques } \\
\text { - tracts }\end{array}$ \\
\hline $\begin{array}{l}\text { "Groupe des } \\
\text { dix-huit » }{ }^{74}\end{array}$ & - 23 octobre & $\begin{array}{l}\text { - déclaration publique } \\
\text { - délégation reçue par le président }\end{array}$ \\
\hline A. Ben Bella ${ }^{75}$ & - octobre-novembre & $\begin{array}{l}\text { - multiplication des déclarations et } \\
\text { interviews dans la presse nationale et } \\
\text { internationale }\end{array}$ \\
\hline H. Aït-Ahmed ${ }^{76}$ & - octobre-novembre & $\begin{array}{l}\text { - multiplication des déclarations et } \\
\text { interviews dans la presse nationale et } \\
\text { internationale }\end{array}$ \\
\hline
\end{tabular}

Sources : Tableau élaboré par nos soins sur la base de plusieurs types de sources présentés plus haut (voir note 11).

71. Contrairement à la première, cette ligue des droits de l'homme dirigée par $\mathrm{M}^{\mathrm{e}}$ Miloud Brahimi, a été créée avec le soutien du ministre de l'Intérieur en 1987.

72. Militants du Mouvement culturel berbère (MCB), notamment Saïd Sadi, Mokrane et Areski Aït-Larbi, Ferhat M'henni (qui ont créé la LADDH non officielle). Ils comptent parmi les principaux animateurs du " printemps berbère » d'avril 1980 (organisation de diverses mobilisations pour la promotion de la langue berbère et la défense de la liberté d'expression). Ces militants sont essentiellement étudiants à Alger et à Tizi-Ouzou.

73. Anciennes combattantes de la guerre d'indépendance (tract non nominalement signé).

74. Il rassemble essentiellement des anciens dirigeants de premier plan sous la présidence de H. Boumediene, évincés par Chadli au début des années 1980 : notamment M. S. Yahiaoui, A. Bouteflika, B. Abdesslam, L. Bentobal. Algérie-Actualité, 10-16 novembre 1988 ; Horizon, 31 octobre 1988.

75. Premier président de la République algérienne, il est destitué après le coup d’État de H. Boumediene, le 19 juin 1965, avant d'être emprisonné puis assigné à résidence et gracié par Chadli en 1980. Il s'exile alors en Suisse, puis en France, où il fonde le MDA : Ahmed Ben Bella, Itinéraire, Alger, Éditions Maintenant, 1987.

76. Il est l'un des principaux fondateurs du FLN. Député à l'Assemblée constituante, il s'oppose au régime de Ben Bella et anime une rébellion armée en Kabylie en 1963 sous l'égide du FFS, qu'il crée le 19 septembre 1963. Il est arrêté, condamné à mort, puis gracié. Il s'évade de prison en 1966, puis s'exile en France et en Suisse. 


\section{De la dénonciation de la répression à la dénonciation du régime FLN}

De la même façon que chez les islamistes, les propos tenus lors de ces diverses mobilisations se centrent d'abord sur la répression. Des médecins organisent des assemblées générales dans leurs centres médicaux universitaires afin de diffuser des informations sur le nombre de blessés par balles explosives et les mauvais traitements infligés aux jeunes émeutiers arrêtés ${ }^{77}$. Ils participent à la création, par des universitaires algérois, d'un Comité national contre la torture ${ }^{78}$. Ils collaborent avec des avocats qui prennent gracieusement la défense de jeunes arrêtés. Ils sont également sollicités par les responsables de la LADH (reconnue par l'État) qui s'engagent rapidement dans la rédaction d'un rapport sur la torture et qui annoncent dès la fin des émeutes un bilan accablant fondé sur des sources médicales ${ }^{79}$. Les connexions entre personnes issues de divers milieux professionnels sont nombreuses. Des passerelles entre les différents groupes mobilisés se mettent ainsi rapidement en place afin de documenter des cas de torture et d'arrestations arbitraires, comme le souligne $\mathrm{M}^{\mathrm{e}}$ Miloud Brahimi, président de la LADH : « [À la Ligue], nous étions en relation avec tous les acteurs concernés, les médecins, les journalistes, etc.» (Entretien.) La prise en charge de cette question par des personnalités issues de secteurs socioprofessionnels nombreux et diversifiés (avocats, médecins, journalistes, étudiants, enseignants ${ }^{80}$ ) en permettra aussi une large diffusion. Par ailleurs, une partie de la presse algérienne s'en emparera. Le très officiel El Moudjahid rend notamment compte du travail de la commission d'enquête de la LADH installée le 20 octobre $^{81}$. Algérie-Actualité, dont la ligne éditoriale est souvent plus critique, divulgue des extraits accablants de ce rapport : « La torture a été pratiquée à grande échelle. [...] Les auteurs de tir ont parfois agi avec une volonté délibérée de tuer. [...] Les forces de l'ordre ont utilisé des balles explosives ${ }^{82}$.» L'hebdomadaire publie de nombreux témoignages de jeunes garçons torturés ${ }^{83}$. L'ouvrage du Comité national contre la

77. Abdenbi (K.), « Octobre 1988 et l'engagement des médecins », in Le Saout (D.), et Rollinde (M.), dir., Émeutes et mouvements sociaux au Maghreb..., op. cit.

78. Benmalek (A.), « La formation du Comité national contre la torture en Algérie », dans Le Saout (D.), Rollinde (M.), dir., Émeutes et mouvements sociaux au Maghreb..., op. cit.; Morsly (D.), " Octobre 1988 : "plus jamais ça" ", in Semiane (S.-A.), dir., Octobre, ils parlent, op. cit.

79. Algérie-Actualité, 27 octobre-2 novembre 1988 ; L’Humanité, 14 octobre 1988.

80. Des médecins organisent une marche dans l'enceinte de l'hôpital Mustapha à Alger pour dénoncer la torture (Le Figaro, $1^{\text {er }}$ novembre 1988). Sur les actions d'universitaires, voir Le Monde, 21 octobre 1988 et Algérie-Actualité, 27 octobre-2 novembre 1988. Des milliers d'étudiants se rassemblent régulièrement ( $L e$ Figaro, 8 novembre 1988 ; L'Humanité, 24 octobre 1988). Des journalistes se réunissent également à plusieurs reprises dans le même but (Le Monde, 12 octobre 1988 ; Libération, 18 octobre 1988). Voir Lazhari Labter, "Notre plus belle conquête ", in Sémiane (S.-A.), dir., Octobre, ils parlent, op. cit. Pour les avocats, voir Algérie-Actualité, 20-26-octobre 1988. Pour les mobilisations contre la torture des berbéristes et de la LADDH (non officielle), cf. Algérie-Actualité, 27 octobre-2 novembre 1988. Pour les anciennes combattantes de la guerre d'Alger, cf. Algérie-Actualité, 27 octobre-2 novembre 1988. Pour les anciens hommes politiques déchus, cf. Horizon, 31 octobre 1988 et Le Figaro, 8 octobre 1988.

81. El Moudjahid, 21-22 octobre 1988.

82. Algérie-Actualité, 14-21 novembre 1988.

83. Algérie-Actualité, 2-8 novembre 1988. 
torture, créé lors d'une réunion à l'université de Bab Ezzouar, le 17 octobre, est diffusé quelques semaines plus tard et bénéficie d'un grand retentissement ${ }^{84}$. Les avocats, signataires de communiqués et de lettres publiques adressées au président, recueillent des informations sur les conditions d'arrestation et de détention des jeunes émeutiers qu'ils font circuler dans les cercles algérois mobilisés. La diffusion de leurs témoignages sur « des détentions arbitraires, des tortures, des sévices ${ }^{85}$ » souligne combien certains médias sont impliqués dans ces actions. C'est donc dans un premier temps par le truchement de la dénonciation de la répression que l'on observe une "désectorisation de l'espace social ${ }^{86}$ ", caractéristique des situations de crise politique. On observe en effet l'effacement brutal des frontières entre secteurs et l'intensification de leur interdépendance, caractéristique d'une conjoncture de fluidité politique.

La dénonciation de la répression constitue le levier à partir duquel se formulent des revendications politiques qui prennent deux formes principales. D’une part, les divers collectifs plus ou moins formels d'étudiants, de médecins, de journalistes et d'universitaires promeuvent des revendications catégorielles. Les journalistes, par exemple, critiquent le caractère non représentatif de l'organisation à laquelle ils sont rattachés, l'Union des journalistes, écrivains et interprètes (UJET) qui est, selon les statuts du FLN, le « prolongement naturel du parti ${ }^{87}$ ». Ils annoncent la création d'une organisation " autonome, démocratique, unitaire et pluraliste ${ }^{88}$ ». De même, des médecins et des étudiants déclarent leur intention de créer des structures indépendantes du parti unique, seules capables de représenter leurs intérêts contre les organisations du FLN ${ }^{89}$. Il en est de même des universitaires algérois, comme le précise Ali Brahimi, professeur à l'Université de sciences à Bab-Ezzouar : "On a organisé plusieurs assemblées générales. [...] On a pris contact avec des profs dans d'autres facs. [...] À partir de l'université, j'ai participé à la revendication de la création de mouvements syndicalistes autonomes. On demandait la fin du monopole syndical de l'UGTA. » (Entretien.) Ces revendications catégorielles sont autant de mises en cause du dispositif institutionnel en vigueur, puisque le contrôle partisan de toute activité organisée (vie étudiante, secteurs professionnels, univers culturels, etc.) constitue la pierre angulaire du régime du parti unique.

Toutefois, au sein de certains collectifs se développe une critique plus large et plus radicale de l'État algérien. C'est ce qu'expriment notamment les avocats : «Les origines des difficultés économiques du pays (sécheresse, baisse des prix

84. Comité national contre la torture, Cahier noir d'octobre, op. cit.

85. Algérie-Actualité, 27 octobre-2 novembre 1988.

86. Dobry (M.), Sociologie des crises politiques, op. cit., p. 140 et suiv.

87. Article 119 des statuts du $5^{\mathrm{e}}$ congrès du FLN, 19-23 décembre 1983.

88. Libération, 18 octobre 1988. Cf. Ancer (A.), Encre rouge. Le défi des journalistes algériens, Alger, Éditions El Watan, 2001, p. 53-68.

89. Algérie-Actualité, 27 octobre-2 novembre 1988 ; Libération, 24 octobre 1988. 
du pétrole, etc.) sont autant de mobiles, mais sans être pour autant des justifications de ce qui est advenu. Les émeutes n'auraient jamais revêtu ce caractère anarchique et destructeur si les manifestants avaient eu réellement la possibilité de dire librement leur malaise et leurs opinions dans les formes pacifiques que toute législation de pays démocratique se doit de prévoir. Le mal est plus profond et plus lointain ${ }^{90}$. " Tracts et discours appellent à instaurer les « libertés démocratiques ${ }^{91}$ » et dénoncent la dégradation des conditions de vie de la population. On le voit, les termes utilisés, similaires d'un groupe à l'autre, se rapprochent de ceux des leaders de la da'wa, à l'exception bien sûr de la revendication du renforcement de la place de la religion. Ici aussi les émeutiers sont les victimes du régime FLN et non plus des "voyous », tandis que des solutions politiques générales de sortie de crise sont formulées. Hocine Aït-Ahmed exige la mise en place d'un " gouvernement d'unité nationale dans le but d'organiser des élections libres en vue de l'élection d'une Assemblée nationale constituante ». Quant aux « dix-huit », déchus de leurs fonctions politiques quelques années plus tôt par Chadli, ils réclament l'organisation d'une " conférence nationale » regroupant « l'ensemble du personnel politique depuis l'indépendance » (donc eux-mêmes), pour définir des « réformes institutionnelles capables de garantir les libertés démocratiques ${ }^{92}{ }^{2}$. Ils appellent explicitement les autorités, au premier rang desquelles le président de la République, à apporter une réponse institutionnelle aux émeutes, sans toutefois réclamer explicitement le pluralisme partisan.

Pour l'ensemble des acteurs mobilisés, les émeutes fonctionnent donc comme le révélateur des problèmes politiques et sociaux de l'Algérie. Ces problèmes sur ce point aussi l'ensemble des acteurs contestataires convergent - ne trouveront de solution qu'à travers une entreprise de libéralisation politique. Cette grille d'interprétation s'oppose donc frontalement à celle des instances militaires, du gouvernement et du FLN, qui ne retenaient des émeutes que la destruction sans motif. À la question de savoir pourquoi la première grille d'interprétation s'est progressivement imposée pour ensuite recouvrir complètement la seconde, l'émoi réel suscité par la violente répression policière ne suffit pas.

\section{La mobilisation de ressources et de réseaux militants antérieurs}

Leur expérience militante passée constitue en effet un élément central pour saisir l'engagement de ces divers groupes à l'automne 1988. Les principaux initiateurs des mobilisations de soutien aux émeutiers ont, au cours de la décennie précédente, participé à d'autres actions protestataires. Ces expériences

\footnotetext{
90. Charef (A.), Octobre 1988, un chahut de gamins ?, op. cit., p. 225-226.

91. Horizon, les 19 et 31 octobre 1988 ; Radio-Beur, Octobre à Alger, op. cit., p. 121-123; Saïd Sadi, Le RCD à cour ouvert, Alger, Éditions Parenthèses, 1990, p. 85.

92. Horizon, 31 octobre 1988.
} 
passées leur ont permis d'acquérir des savoir-faire qui seront réactivés pendant les émeutes : rédaction de tracts et de communiqués, animation de réunions, organisation de manifestations, contacts avec la presse, etc. En octobre et novembre 1988, le choix se porte vers des répertoires d'action qu'ils maîtrisent, qui leur sont familiers. Des étudiants organisent par exemple le même type d'assemblées générales et de rassemblements dont ils sont coutumiers depuis les mobilisations de $1987^{93}$. C'est aussi le cas des berbéristes, comme Saïd Khelil, Mouloud Louanouci ou Saïd Sadi qui refont en octobre 1988 ce qu'ils avaient déjà fait en 1980 pendant le « printemps berbère ${ }^{94} »$ : organisation d'une grève générale et diffusion de tracts. Il en est de même pour les imams mobilisés qui ont expérimenté dans la dernière décennie un certain nombre de modes d'action qui seront réactivés au moment des émeutes : diffusion de tracts et rassemblements dans et autour des mosquées ${ }^{95}$. Ces compétences dans l'organisation de mobilisations, qui constituent autant de ressources précieuses, assureront une action efficace. Elles permettront également d'agréger rapidement de nombreuses personnes qui n’ont jamais milité dans le passé et qui s'engagent dans les semaines qui suivent les émeutes pour la première fois.

Par ailleurs, ces mobilisations préalables ont progressivement permis l'établissement de relations entre des individus issus de milieux très divers. La majorité des initiateurs des mobilisations d'octobre 1988 se sont fréquentés dans le cadre de leurs activités antérieures, professionnelles et/ou politiques. Areski Aït-Larbi (ancien étudiant en médecine, militant berbériste et fondateur de la première ligue des droits de l'homme en 1985), cas typique de militant multipositionné, inséré simultanément dans plusieurs groupes contestataires, le souligne : «J'étais connecté avec un peu tout le monde, j'étais en quelque sorte le représentant du groupe de Tizi-Ouzou dans tous les groupes. [...] Mais j'en connaissais certains avant. » (Entretien.) C'est également le cas de journalistes, d'universitaires ou d'artistes mobilisés en 1988, qui ont en plusieurs occasions soutenu les « berbéristes » emprisonnés quelques années plus tôt ${ }^{96}$. Le cas des leaders du « printemps berbère » d'avril 1980 est emblématique. En octobre 1988, à Alger ou à Tizi-Ouzou, ils agissent selon les moments au nom du Mouvement culturel berbère (MCB), sous le sigle des comités universitaires, en tant que médecins (beaucoup d'entre eux le sont) pour la constitution d'une organisation indépendante

\footnotetext{
93. Les mobilisations d'octobre 1988 rassemblent d'anciens leaders des comités de coordination créés à l'occasion des grèves estudiantines de 1986, Le Monde, 25 octobre 1988. Kacentini (T.), « Luttes étudiantes à Constantine. Les événements de novembre 1986 ", Annuaire de l'Afrique du Nord, tome 25, 1986, p. 281-295. 94. Sur les mobilisations berbéristes de 1980, Chaker (S.), "Journal des événements de Kabylie (mars-mai 1980) », Les Temps modernes, 232-233, juillet-août 1982, p. 383-435.

95. Dont le rassemblement de novembre 1982 évoqué plus haut qui s'était accompagné de la diffusion d'une plate-forme de revendications. Pour plus de détails sur les mobilisations antérieures dans la da'wa, voir Aït-Aoudia (M.), « La naissance du FIS. Une politisation conflictuelle », Critique internationale, 30, 2006. 96. Collectif contre la répression en Algérie, Au nom du peuple..., op. cit., p. 225-252 ; Collectif contre la répression en Algérie, Algérie : les droits de l’homme, revue de presse, Paris, 24 décembre 1985.
} 
du FLN, ou encore en tant que fondateurs de la LADDH. Mokrane Aït-Larbi, avocat et militant, associé à la fois aux milieux hospitaliers, universitaires et « berbéristes » à Alger comme à Tizi-Ouzou raconte : « [Concernant les actions collectives organisées avant les émeutes], on était $\mathrm{MCB}$, mais on ne signait pas MCB. On signait : "AG de l'université", "comité contre la répression", "ligue des droits de l'homme", "syndicat", "coordination", etc. On n'utilisait pas le sigle MCB sur les tracts. On n'a jamais, avant l'appel du 9 novembre 1988, terminé un tract par "MCB". Généralement c'était “coordination", c'est-à-dire les militants MCB élargis aux syndicats, à la ligue, aux enfants de chouhadas [combattants morts pendant la guerre de libération], etc. En fait, c'était toujours les mêmes personnes, les mêmes animateurs. »(Entretien.) D’anciennes relations entre camarades sont ainsi réactivées au lendemain des émeutes d'octobre 1988. Elles constituent ainsi un autre levier de la désectorisation inédite de l'espace social au lendemain des émeutes. Ces liens préalablement noués facilitent la constitution de passerelles entre les différents groupes mobilisés, et par là, conferent une forte visibilité au mouvement. Tous se mobilisent ensemble pendant les émeutes. Les relations professionnelles jouent également un rôle central : c'est notamment le cas de journalistes et de médecins, en mesure de rallier rapidement de nombreux collègues. Les divers secteurs au sein desquels les acteurs se mobilisent deviennent ainsi rapidement interdépendants. Des ressources jusque-là cloisonnées au sein de chaque secteur se trouvent directement confrontées les unes aux autres et tirent leur efficacité de cette confrontation même ${ }^{97}$.

Enfin, les revendications formulées pendant les émeutes sont similaires à celles déjà exprimées depuis plusieurs années par certains des porte-parole des groupes mobilisés. On l'a noté plus haut, c'est le cas des islamistes. C'est aussi le cas de Hocine Aït-Ahmed réclame depuis 1963 la création d'une «Assemblée nationale constituante ${ }^{98}$ ", exigence qui constitue le cœur de son discours au lendemain des émeutes d'octobre 1988. Il en est de même de la demande de création de "syndicats autonomes et représentatifs pour les travailleurs, étudiants, paysans » par les leaders du parti communiste ${ }^{99}$. Des médecins, des journalistes et des étudiants aussi réclament depuis longtemps la possibilité de créer des structures professionnelles indépendantes du parti unique ${ }^{100}$. Les demandes

97. Dobry (M.), Sociologie des crises politiques, op. cit.

98. Redjala (R), L'opposition en Algérie depuis 1962. Tome 1. Le PRS-CNDR, le FFS, Paris, L'Harmattan, 1988 ; Guenoun (A.), Chronologie du mouvement berbère, 1945-1990. Un combat et des hommes, Alger, Casbah Éditions, 1999.

99. Taleb (A.), « Les rapports parti-syndicat en Algérie à travers l'application de l'article 120 des statuts du FLN », Annuaire de l'Afrique du Nord, tome 21, 1982.

100. Depuis 1987, des journalistes de divers organes de la presse écrite et de la radio algérienne se rassemblent régulièrement dans un informel Mouvement des journalistes algériens (MJA), qui s'oppose à la très officielle Union des journalistes, écrivains et interprètes (UJET). Le 9 mai 1988, le jeune MJA adresse une plate-forme de revendications au ministre de l'Information. Cf. Ancer (A.), Encre rouge..., op. cit., p. 22-52. De nombreux médecins d'Alger et de Tizi-Ouzou (et/ou d'anciens étudiants en médecine) mobilisés en octobre, militent dans les années 1980 au MCB, puis à la LADDH. C'est notamment le cas de Saïd Khelil, 
des «berbéristes » et, du même coup, des fondateurs de la première Ligue des droits de l'homme, sont particulièrement éloquentes puisque les revendications de 1988 reprennent quasiment mot pour mot celles des années précédentes : en avril 1980, « la reconnaissance de la culture et de la langue berbères comme partie intégrante du patrimoine culturel national [...] la liberté effective d'expression, d'opinion et de pensée ${ }^{101}$ »; en juin 1985, « la promotion des droits de l'homme ${ }^{102}$ ", et en octobre et novembre 1988, " la reconnaissance et prise en charge de la langue et des cultures berbères, [...], pour les libertés démocratiques, la justice sociale et les droits de l'homme ${ }^{103} »$. La similarité des revendications est frappante. Ainsi, une partie des acteurs mobilisés en octobre et novembre 1988 se saisit du nouveau contexte créé par les émeutes et leur répression comme d'une " opportunité ${ }^{104}$ » pour faire valoir des revendications anciennes et se ménager une place dans un débat public. Ils agrègent néanmoins bien au-delà du cercle des anciens activistes de la dernière décennie qui se sont opposés au régime de parti unique. En se rapportant à son expérience passée ${ }^{105}$, chaque collectif se saisit des actions initiées par d'autres, de sorte que les mobilisations se consolident et se renforcent, les unes entrainant les autres dans une spirale ascendante. La progressive coordination entre groupes jusqu'alors dispersés autorise la circulation des informations et contribue à l'homogénéisation des discours. La légitimité des actions et des revendications est d'autant plus forte que les actions se multiplient et sont soutenues par une pluralité d'acteurs sociaux et politiques dont le cercle s'élargit.

Face à la diversité, à la concomitance et à la visibilité médiatique de ces actions de contestation politique, les autorités civiles et militaires cessent la répression et abandonnent progressivement le discours de disqualification et de criminalisation des jeunes émeutiers, prélude à l'amorce d'un changement politicoinstitutionnel de grande ampleur. Les émeutes d'octobre 1988 deviennent alors

qui dirigeait la section de l'Union médicale algérienne (UMA) à Tizi-Ouzou, de S. Sadi, M. Lounaouci (Tizi-Ouzou), A. Aït-Larbi, M. Baraka, ou encore M. Boucebci (Alger). Le comité de Tizi-Ouzou de l'UMA a organisé, à plusieurs reprises dans les années 1980, des actions de soutien pour les militants arrêtés lors du printemps berbère d'avril 1980 et de la création de la LADDH. De plus, les actions de ces médecins portaient également dans les années 1980 sur la nécessité d'autonomiser l'UMA du FLN.

101. Guenoun (A.), Chronologie du mouvement berbère..., op. cit., p. 205-206.

102. Collectif contre la répression en Algérie, Au nom du peuple..., op. cit., p 31 et 59-73.

103. Ibid.

104. Sur le biais objectiviste de la notion de "structure d'opportunités politiques » et la nécessité d'être attentif aux perceptions des acteurs en situation, voir Fillieule (O.), « Requiem pour un concept. Vie et mort de la notion de structure des opportunités politiques ", in Dorronsoro (G.), dir., La Turquie conteste. Mobilisations sociales et régime sécuritaire, Paris, CNRS Éditions, 2005.

105. Dans une perspective proche qui s'attache à la fois à la dynamique de mobilisations multisectorielles en situation et à la réactivation d'engagements et de conflits passés des divers acteurs mobilisés, voir Gobille (B.), «L'événement Mai 68. Pour une sociohistoire du temps court », Annales, 63 (2), 2008. 
l'acte de naissance de la démocratisation algérienne. Des prolongements de la notion de « protagonisme » qui saisit l'élargissement inédit de la participation politique dans l'événement révolutionnaire, peuvent être tirés du cas algérien. D’une part, la qualification politique de l'événement ne peut être imposée en surplomb par le chercheur - souvent à partir d'une analyse ex post. Il faut au contraire être attentif aux luttes pour la définition légitime de l'événement, en situation, et restituer le processus par lequel une définition tend à s'imposer à tous les protagonistes, tandis que des catégorisations concurrentes sont écartées ${ }^{106}$. Les fixations sémantiques n'importent en effet que dans la mesure où elles sont produites par les acteurs dans le cours de l'action. D'autre part, produire une parole politique sur l'événement n'a rien d'évident, tout comme le succès de cette interprétation politique. Si les émeutiers, individus ordinaires tenus jusque-là à l'écart de la vie publique, ouvrent l'espace des possibles, ce sont bien des acteurs déjà engagés dans le passé qui médiatisent leur action et imposent un sens politique et contestataire à l'événement. Les caractéristiques mêmes de l'émeute - désorganisée, sans mots d'ordre, menée par de très jeunes gens qui n'articulent aucune parole politique, ou si peu - permettent la production extérieure de cette parole politique. La dénonciation de la répression constitue le premier levier de la mobilisation de militants issus de plusieurs secteurs sociaux qui vont progressivement se constituer comme les porte-parole d'émeutiers disqualifiés et criminalisés par les autorités institutionnelles. Ces acteurs préalablement politisés s'emparent donc de l'événement, constituent des passerelles solides entre divers secteurs sociaux, s'appuient sur des ressources et des réseaux militants antérieurs. L' " amplification ${ }^{107}$ » de l'événement, c'est-à-dire son retentissement et son intensification, n'est donc pas due dans notre cas à des émeutiers devenus protagonistes au sens de H. Burstin, mais à des militants qui parviennent à imposer leur position politique dans l'espace public dans un contexte de grande incertitude.

Myriam Aïт-Aoudı est maître de conférences en science politique à Sciences Po Bordeaux - Université de Bordeaux et chercheuse au Centre Émile Durkheim. Elle a récemment publié : L'expérience démocratique en Algérie (1988-1992). Apprentissages politiques et changement de régime, Paris, Presses de Sciences Po, 2015 ; et coordonné avec Antoine Roger, La logique du désordre. Relire la sociologie de Michel Dobry, Paris, Presses de Sciences Po, 2015.

m.ait.aoudia@sciencespobordeaux.fr

\footnotetext{
106. Dobry (M.), « Révolutions, crises, transitions », in Fillieule (O.), Mathieu (L.), Péchu (C.), dir., Dictionnaire des mouvements sociaux, Paris, Presses de Sciences Po, 2009, p. 475-477.

107. Burstin (H.), « Le "protagonisme" comme facteur d'amplification de l'événement : le cas de la Révolution française ", in L'événement (Actes du colloque organisé à Aix-en-Provence par le Centre méridional d'histoire sociale, septembre 1983), Aix-en-Provence, Université de Provence, 1986.
} 